\title{
Improved MPPT controls for a standalone PV/wind/battery hybrid energy system
}

\author{
Otmane Zebraoui, Mostafa Bouzi \\ Department of Electrical Engineering, Faculty of Sciences and Technology, Hassan First University, Morocco
}

\begin{tabular}{|c|c|}
\hline Article Info & ABSTRACT \\
\hline Article history: & In this paper, we present the modeling, optimization and control of \\
\hline Received Jul 16, 2019 & a standalone hybrid energy system combining the photovoltaic and wind \\
\hline Revised Nov 9, 2019 & batteries as a backup source. With the aim of improving the energy \\
\hline Accepted Jan 1, 2020 & $\begin{array}{l}\text { performance of the proposed system, we developed an MPPT controller } \\
\text { based on new hybrid and robust approaches to evolve the power quality }\end{array}$ \\
\hline Keywords: & $\begin{array}{l}\text { produced by both PV and Wind subsystems. For the PV subsystem, } \\
\text { the proposed approach is based on the methods perturb and observe (P\&O), }\end{array}$ \\
\hline Fuzzy logic control & sliding mode control (SMC) and fuzzy logic control (FLC). For the Wind \\
\hline Hybrid energy system & $\begin{array}{l}\text { subsystem, the proposed technique is based on the hill climbing search } \\
\text { algorithm (HCS) and the fuzzy logic control. Also, to evaluate the efficiency }\end{array}$ \\
\hline MPPT & of the developed controls and to analyze the behavior of each system \\
\hline Photovoltaic system & during their maximum power point tracking, a comparison study was \\
\hline Sliding mode control & carried out with conventional techniques and the simulations are performed \\
\hline Wind system & $\begin{array}{l}\text { under varying weather conditions. The simulations results show } \\
\text { the good performance of the proposed MPPT controls compared to other } \\
\text { methods with better response time, a higher optimal power point and } \\
\text { negligible oscillations. }\end{array}$ \\
\hline
\end{tabular}

This is an open access article under the CC BY-SA license.

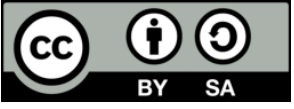

\section{Corresponding Author:}

Otmane Zebraoui,

Department of Electrical Engineering,

Faculty of Sciences and Technology,

Hassan First University, BP: 577, Route de Casablanca, Settat, Morocco.

Email: otmanezebraoui@gmail.com

\section{INTRODUCTION}

In recent years, the electrification of isolated sites presents a problem and a global interest due to difficulties to realize the electrical grid extension, and the disadvantages of conventional energy sources based on fossil fuels because they are polluted, very expensive and available with limited quantities. To overcome these problems the interest is attracted to renewable energy sources such as solar and wind because they are clean, economic and available sources, they present an alternative and promising solution to satisfy energy demands efficiently. Despite the advantages and growing development of these technologies, they remain dependent on climatic conditions, namely, solar irradiation, temperature and wind speed, which disrupts the systems energy production and therefore the risk of losing tracking of the power required by the load. For this reason, one of the solutions proposed to avoid this problem is the combination of two or more energy sources of different technologies, such as photovoltaic and wind, to compose a hybrid system with or without storage batteries. This presents considerable advantages over the single-source system to ensure a continuous and autonomous supply of electrical load whatever the weather changes [1]. In the literature, there are several architectures of the hybrid energy system have been proposed [2-5], with 
research work on the optimization of their sizing and improving the energy performances of photovoltaic and wind generators thanks to development and implementation of intelligent MPPT control techniques [6, 7].

In this work, we propose a hybrid architecture that can be used as a stand-alone application in isolated sites. It combines a photovoltaic generator with a wind system based on a permanent magnet synchronous generator (PMSG), which are considered as the main power sources to supply a DC electrical load, also a storage system based on lithium-ion batteries is used as a backup source to intervene where the two subsystems energy production becomes insufficient to meet the load needs. In order to optimize the energy efficiency of the proposed hybrid system, we focused our study on the development of an MPPT controller based on two innovative approaches to improve the energy productivity of both PV and Wind subsystems.

In the literature, several methods have been developed, namely, the algorithm of Perturb and observe (P\&O) for PV system [8] or Hill Climbing Search (HCS) for Wind system [9], the intelligent Fuzzy Logic Control (FLC) [10,11] and the non-linear Sliding Mode Control (SMC) [12, 13]. Each of these methods has advantages and disadvantages that can be summarized by $[14,15]$ : The P\&O or HCS algorithm present significant oscillations around the optimal power point which increases the energy losses. The SMC technique has good accuracy and stability around the MPP with a robust tracking under the operating conditions variation, but its major disadvantage is the chattering phenomenon that decreases this technique efficiency [16]. The FLC technique has good performance with a better dynamic response to stabilize the systems around these MPP points, as well it has good transient behavior under variations in climatic conditions. However, our objective is the development of hybrid approaches based on these techniques in order to exploit their advantages and consequently obtain controls with good efficiency compared to conventional techniques. For the PV subsystem, we propose a hybrid control decomposed under three parts, the first is to calculate a reference voltage by the $\mathrm{P} \& \mathrm{O}$ algorithm to improve the system response time, and this reference parameter is used after in both next steps based on SMC and FLC techniques. The SMC part allows increasing the system accuracy and that of the FLC allows improving the dynamic response, to reduce the oscillations and the chattering phenomenon around the MPP. For the Wind subsystem, we propose a control technique based on a reference step that allows calculating two parameters used after to determine the input variables of a fuzzy controller, using the HCS algorithm and the optimal characteristics of the wind turbine.

This paper is structured as follows: The proposed hybrid energy system architecture is described in the following section with detailed modeling of each system component. In Section 3, we present the proposed MPPT control approaches to improve the performances of both PV and Wind subsystems. The performed simulations results with their analysis and discussion are presented in section 4. Finally, in section 5, the conclusions of this work are given with our perspectives in future works

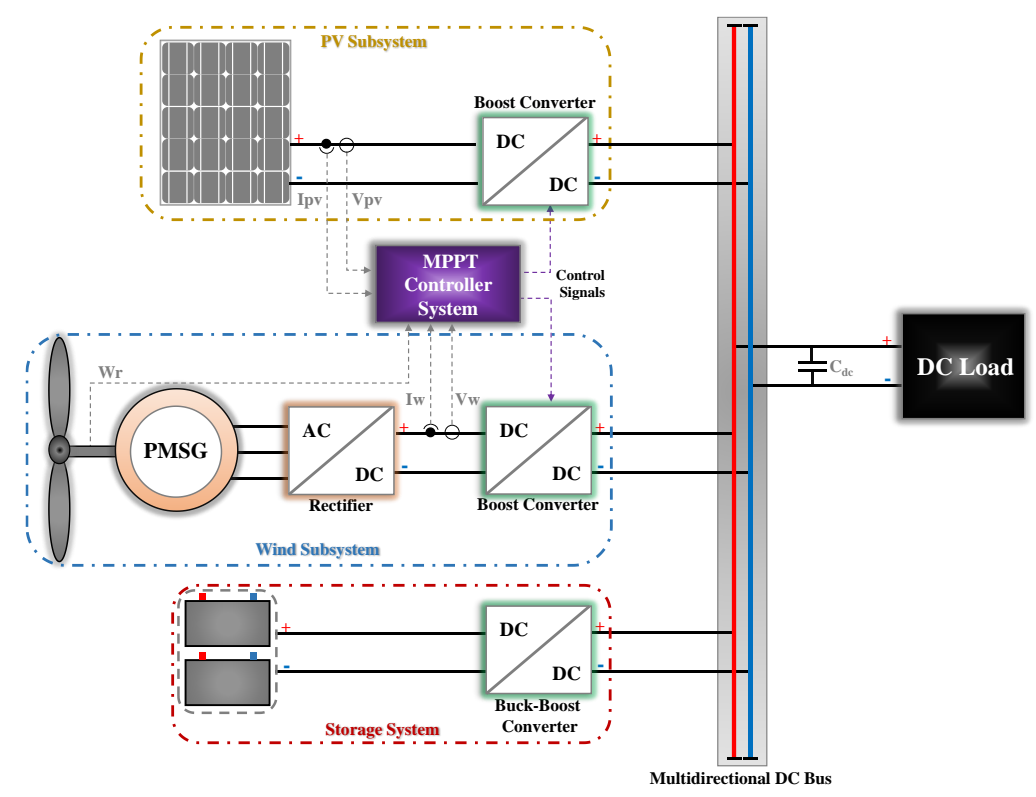

Figure 1. Hybrid energy system architecture 


\section{HYBRID ENERGY SYSTEM: DESCRIPTION AND MODELING}

Figure 1 presents the configuration of proposed PV/Wind/Battery hybrid energy system, which includes two renewable energy production subsystems, PV and Wind, and a battery storage system [4, 17]. They are connected in parallel to a DC electrical load through a multidirectional DC bus line. The PV subsystem consists of photovoltaic panels and a dc/dc boost converter. The wind subsystem contains a wind turbine coupled to a permanent magnet synchronous generator (PMSG), ac/dc diode rectifier and dc/dc boost converter. The storage system is based on lithium-ion batteries and a bi-directional buck-boost converter. To optimize the system energy production, an MPPT controller is developed based on two algorithms that allow controlling the two boost converters of both subsystems

\subsection{PV system modeling}

A photovoltaic panel is formed by combining several photovoltaic modules in parallel. Each module includes a defined number of solar cells connected in series to obtain the desired current and voltage at the PV output. By photovoltaic effect, the p-n semiconductor junction of the solar cell converts solar irradiations into electrical energy. Figure 2 shows the equivalent circuit of the single diode PV cell used in this study $[18,19]$, which consists of a current generator in parallel with a diode, a series resistance, and a shunt resistance:

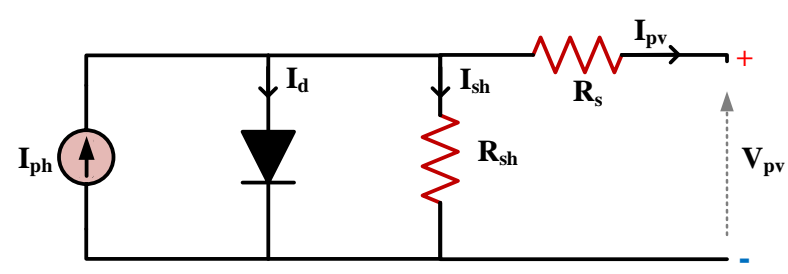

Figure 2. Equivalent circuit of PV cell

Using this equivalent circuit, the current-voltage characteristic (I-V) of the PV cell is obtained by the following equation [18]:

$$
I_{p v}=N_{p} I_{p h}-N_{p} I_{0}\left[\exp \left(\frac{q\left(V_{p v}+\left(N_{s} / N_{p}\right) R_{S} I_{p v}\right)}{N_{S} A K T}\right)-1\right]-\frac{V_{p v}+\left(N_{S} / N_{p}\right) R_{S} I_{p v}}{\left(N_{S} / N_{p}\right) R_{S h}}
$$

Where: $\mathrm{I}_{\mathrm{pv}}$ and $\mathrm{V}_{\mathrm{pv}}$ are the PV array output current and voltage, $\mathrm{I}_{\mathrm{ph}}$ is the PV cell photo-current (A) depends on the solar irradiation $G$ and the temperature $T$ which is described in $(2), I_{0}$ is the reverse saturation current (A) depends on the temperature as given in (3). $R_{s}$ and $R_{s h}$ is the series and the shunt resistance respectively, $\mathrm{N}_{\mathrm{s}}$ is the series cell number, $\mathrm{N}_{\mathrm{p}}$ is the parallel PV modules number, $\mathrm{q}$ is the electron charge $\left(1.602 * 10^{-19} \mathrm{C}\right), \mathrm{K}$ is the Boltzmann constant $\left(1,38^{*} 10^{-23} \mathrm{~J} / \mathrm{K}\right), \mathrm{A}$ is the diode ideality factor and $\mathrm{T}$ is the junction temperature in Kelvin $(\mathrm{k})$.

$$
\begin{aligned}
& I_{p h}=\left[I_{s c}+K_{i}\left(T-T_{\text {ref }}\right)\right] \frac{G}{G_{\text {ref }}} \\
& I_{0}=I_{r s}\left(\frac{T}{T_{\text {ref }}}\right)^{3} \exp \left[\frac{q E_{g}}{A K}\left(\frac{1}{T_{\text {ref }}}-\frac{1}{T}\right)\right]
\end{aligned}
$$

Where: $I_{s c}$ is the short-circuit current at reference conditions, $I_{r s}$ is the saturation current at the reference temperature, the constant $\mathrm{K}_{\mathrm{i}}$ is the short-circuit current temperature coefficient, $\mathrm{E}_{\mathrm{g}}$ is the band-gap energy of the PV cell semiconductor. With the reference conditions are: $\mathrm{T}_{\text {ref }}\left(25^{\circ} \mathrm{C}\right)$ and $\mathrm{G}_{\mathrm{ref}}(1000 \mathrm{~W} / \mathrm{m} 2)$. $\mathrm{In}$ this work, we used the sharp ND-240QCJ PV module, characterized at standard test condition by the electrical parameters listed in Table 1.

Figure 3 shows the P-V characteristics of PV module under different climatic conditions, we observe that the PV module output power increases when the solar irradiation increases, and when the temperature increases the output power decreases, this translates the non-linear behavior of the photovoltaic generator according to solar irradiation and temperature. From These characteristics, we can be remarked that the system has an operating point where the power is maximum, this shows the interest of using a dc/dc converter with MPPT controller to maintain the PV system to its optimum power point. 
Table 1. Electrical parameters of ND-240QCJ PV module

\begin{tabular}{ll}
\hline \multicolumn{1}{c}{ Parameter } & \multicolumn{1}{c}{ Values } \\
\hline Maximum power at STC $\left(\mathrm{P}_{\max }\right)$ & $240 \mathrm{~W}$ \\
Cell serial modules $\left(\mathrm{N}_{\mathrm{s}}\right)$ & 60 \\
Open Circuit Voltage $\left(\mathrm{V}_{\mathrm{oc}}\right)$ & $37.5 \mathrm{~V}$ \\
Maximum Power Voltage $\left(\mathrm{V}_{\mathrm{pm}}\right)$ & $29.3 \mathrm{~V}$ \\
Short Circuit Current $\left(\mathrm{I}_{\mathrm{sc}}\right)$ & $8.75 \mathrm{~A}$ \\
Maximum Power Current $\left(\mathrm{I}_{\mathrm{pm}}\right)$ & $8.19 \mathrm{~A}$ \\
Temperature Coefficient $\left(\mathrm{l}_{\mathrm{sc}}\right) \mathrm{Ki}$ & $0.053 \% /{ }^{\circ} \mathrm{C}$ \\
Temperature Coefficient $\left(\mathrm{V}_{\mathrm{oc}}\right) \mathrm{Kv}$ & $-0.36 \% /{ }^{\circ} \mathrm{C}$ \\
\hline
\end{tabular}

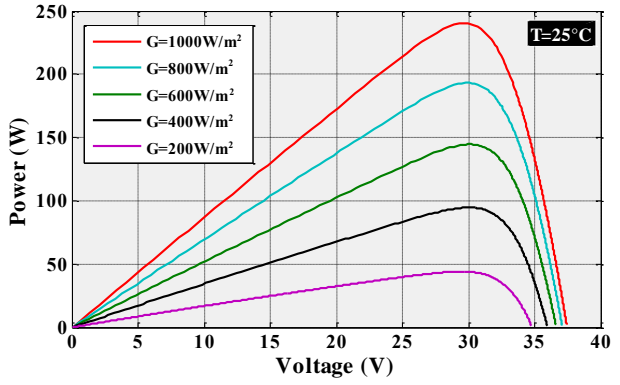

(a)

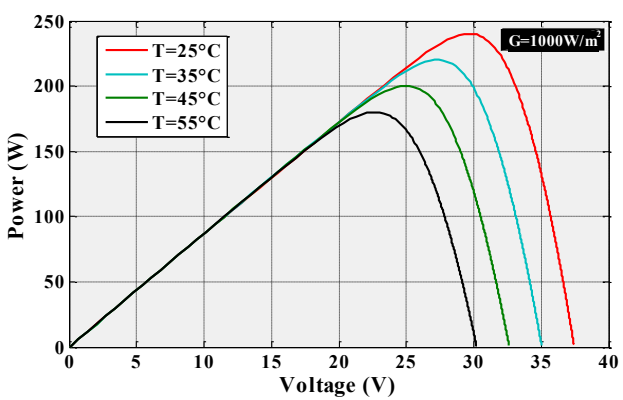

(b)

Figure 3. P-V characteristics for PV module, (a) for various irradiance values at a temperature of $25^{\circ} \mathrm{C}$, (b) for various temperature values at irradiance of $1000 \mathrm{~W} / \mathrm{m}^{2}$

\subsection{Wind system modeling}

For the wind energy production chain, we proposed a system $[6,20]$ consists of a wind turbine that converts the wind kinetic energy into mechanical power thanks to its rotor blades, a permanent magnet synchronous generator PMSG coupled to the turbine that converts mechanical energy into electrical energy, this latter supplies a diode rectifier to convert the AC voltage into DC voltage. And to operate the system at its maximum power point, a dc/dc boost converter with MPPT control is used to obtain and maintain the desired output voltage and power. Mainly, a wind system is modeled by three characteristics, which are the mechanical power Pm, the mechanical torque Tm and the tip speed ratio (TSR). The following equation expresses the output power generated by the wind turbine as a function of the wind speed [2]:

$$
P_{m}=\frac{1}{2} \rho S C_{p}(\lambda, \beta) V_{w}{ }^{3}
$$

Where: $\rho$ is the air density $\left(\mathrm{Kg} / \mathrm{m}^{3}\right), \mathrm{S}$ is the rotor blade swept area, $\mathrm{V}_{\mathrm{w}}$ is the wind speed $(\mathrm{m} / \mathrm{s})$, and $\mathrm{C}_{\mathrm{p}}$ is the power coefficient defines the wind turbine performance, it is given as a function of the rotor blades tip speed ratio $\lambda$ and blade pitch angle $\beta$ by [2]:

$$
C_{p}(\lambda, \beta)=0.5176\left(116 \frac{1}{\lambda_{i}}-0.4 \beta-5\right) e^{\frac{-21}{\lambda_{i}}}+0.0068
$$

where:

$$
\frac{1}{\lambda_{i}}=\frac{1}{\lambda+0.08 \beta}-\frac{0.035}{\beta^{3}+1}
$$

The tip speed ratio $\lambda$ is defined as a function of the wind speed by:

$$
\lambda=\frac{\omega_{r} R}{V_{w}}
$$

Where $\mathrm{R}$ is the wind turbine rotor radius in meters $(\mathrm{m})$ and $\omega_{\mathrm{r}}$ is the wind turbine rotor speed.

The wind turbine output torque $\mathrm{T}_{\mathrm{m}}$ is expressed as the relationship between the output power and the rotor speed, it is given by the following equation: 
$T_{m}=\frac{P_{m}}{\omega_{r}}$

Table 2 summarizes the technical parameters of the wind turbine and PMSG generator used in this work: Figure 4 shows the wind turbine output power $\mathrm{P}_{\mathrm{m}}\left(\omega_{\mathrm{r}}\right)$ as a function of the rotor speed for different wind speed conditions and the power coefficient $C_{p}(\lambda)$ as a function of the tip speed ratio for different pitch angle values $\beta$. For the wind turbine used in this study, the optimal value of $C_{p}$ is equal to 0.48 corresponding to the optimal tip speed ratio $\lambda_{\text {opt }}=8.144$ and to $\beta=0$. According to these characteristics curves, we can be noted that for each wind speed values, the system reaches an operating point where the output power and the power coefficient are maximum. This shows the need for the use of an MPPT algorithm to control the dc/dc converter to track this optimal power point whatever the wind speed conditions.

Table 2. Parameters of wind turbine and PMSG

\begin{tabular}{ll}
\hline \multicolumn{2}{c}{ The Wind turbine } \\
Parameter & Values \\
\hline Nominal Mechanical Output Power & $8.5 \mathrm{~kW}$ \\
$\begin{array}{l}\text { Base Wind Speed } \\
\text { Air Density } \rho\end{array}$ & $12 \mathrm{~m} / \mathrm{s}$ \\
$\begin{array}{l}\text { Pitch Angle } \beta \\
\text { Parameter }\end{array}$ & $1.225 \mathrm{~kg} / \mathrm{m}^{3}$ \\
Number of Pole Pairs & $0^{\circ}$ \\
Stator Phase Resistance & \\
Armature Inductance & Values \\
Friction Factor & 5 \\
Inertia constant & $0.425 \Omega$ \\
\hline
\end{tabular}

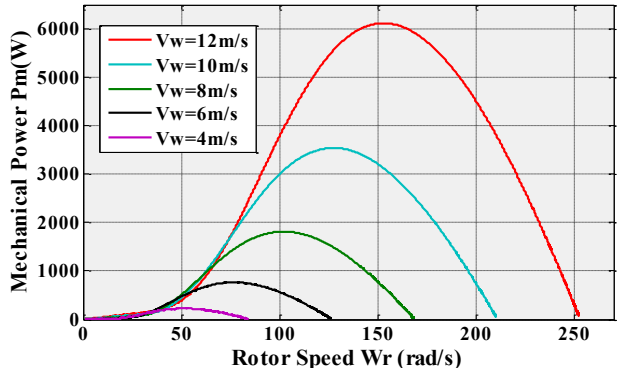

(a)

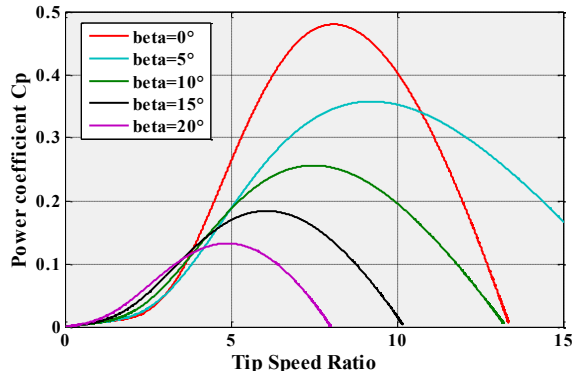

(b)

Figure 4. Wind turbine characteristics, (a) $\mathrm{P}_{\mathrm{m}}\left(\mathrm{V}_{\text {wind }}\right)$ Mechanical power for various values of wind speed (b) Power coefficient for various pitch angle values

\subsection{Boost converter modeling}

In order to optimize the energy efficiency of each power source, we chose to integrate a dc/dc converter as an adaptation interface between each generator (PV or Wind) and the electrical load [4, 6, 17]. The boost converter is considered one of the most used converters in renewable energy applications, including photovoltaic and wind, thanks to its simplicity and efficiency to convert a low dc input voltage into a higher dc output voltage. The principle is based on the control of the converter-switching device (a MOSFET in our case) by a Pulse Width Modulation signal (PWM) generated by the MPPT controller, which ensures to track the maximum power point of each system element [21].

The boost converter output voltage $\mathrm{V}_{\text {out }}$ as a function of the input voltage $\mathrm{V}_{\text {in }}$ (output voltage of PV or Wind generator) is given by [3]:

$$
V_{\text {out }}=\frac{V_{\text {in }}}{1-D}
$$

Where $\mathrm{D}$ is the duty cycle $\left(\mathrm{D}_{\mathrm{pv}}\right.$ or $\left.\mathrm{D}_{\text {Wind }}\right)$.

The boost converter operation that depends on the switching device state (passing or blocking), it can be described by the two following state equations as a function of de duty cycle D (Figure 5)[6]: 


$$
\begin{aligned}
& \frac{d i_{L}}{d t}=\frac{1}{L}\left[V_{\text {in }}-V_{\text {out }}(1-D)\right] \\
& \frac{d V_{\text {out }}}{d t}=\frac{1}{C}\left[i_{L}(1-D)-i_{\text {load }}\right]
\end{aligned}
$$

Where $i_{L}$ is the inductor current and $i_{\text {load }}$ is the load current.

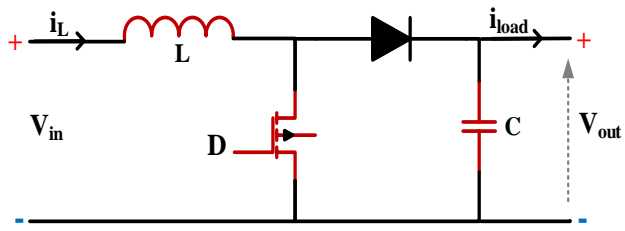

Figure 5. Equivalent boost converter circuit

\section{MPPT CONTROL SYSTEM}

\subsection{Proposed MPPT approach for PV system}

For the PV system MPPT, we propose a hybrid strategy based on the combination of techniques: Perturb and observe (P\&O), Sliding mode control (SMC) and Fuzzy Logic Control (FLC). Figure 6 shows the block diagram of the proposed strategy.

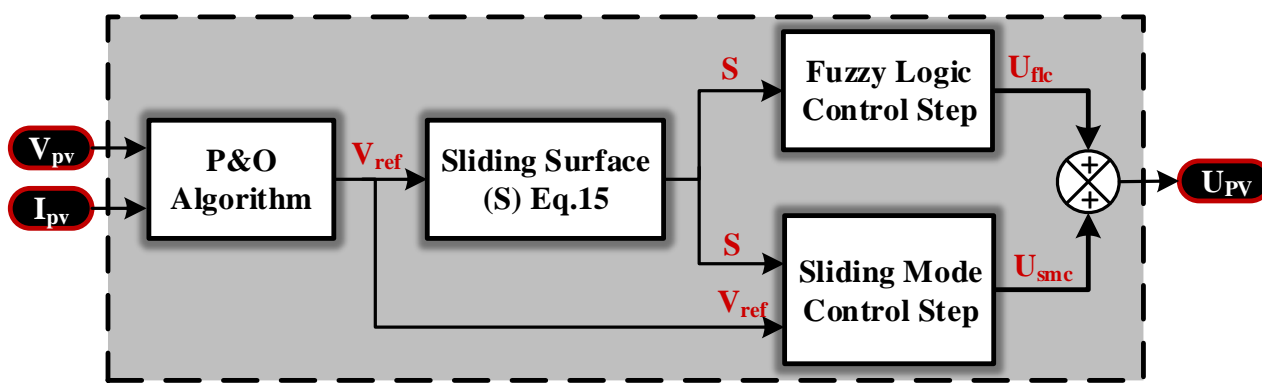

Figure 6. Block diagram of proposed MPPT approach for PV subsystem

The control law is defined by:

$$
\mathrm{U}_{\mathrm{PV}}=\mathrm{U}_{\mathrm{smc}}+\mathrm{U}_{\mathrm{flc}}
$$

To calculate this law, it is necessary to apply the following steps: A P\&O algorithm allows to calculate a reference voltage used to determine a sliding surface by (15), which is used later to calculate the equivalent commands, $\mathrm{U}_{\text {smc }}$ and $\mathrm{U}_{\text {flc }}$, using SMC and FLC techniques respectively.

Figure 7 shows the $\mathrm{P} \& \mathrm{O}$ algorithm [8] used to determine the reference voltage $\mathrm{V}_{\text {ref }}$ that improves the response time and accuracy to find the best MPP point. This algorithm is the most used due to its simplicity; it is based on a small periodic perturbation (incrementing or decrementing) of the PV panel output voltage and the continuous observation of the effect of this perturbation on the PV output power. If a positive perturbation (increase in voltage) increases the output power, the perturbation remains in the same direction until the power starts to decrease, at this moment, the perturbation must reverse the direction (decrease in voltage) to better locate and track the maximum power point. 


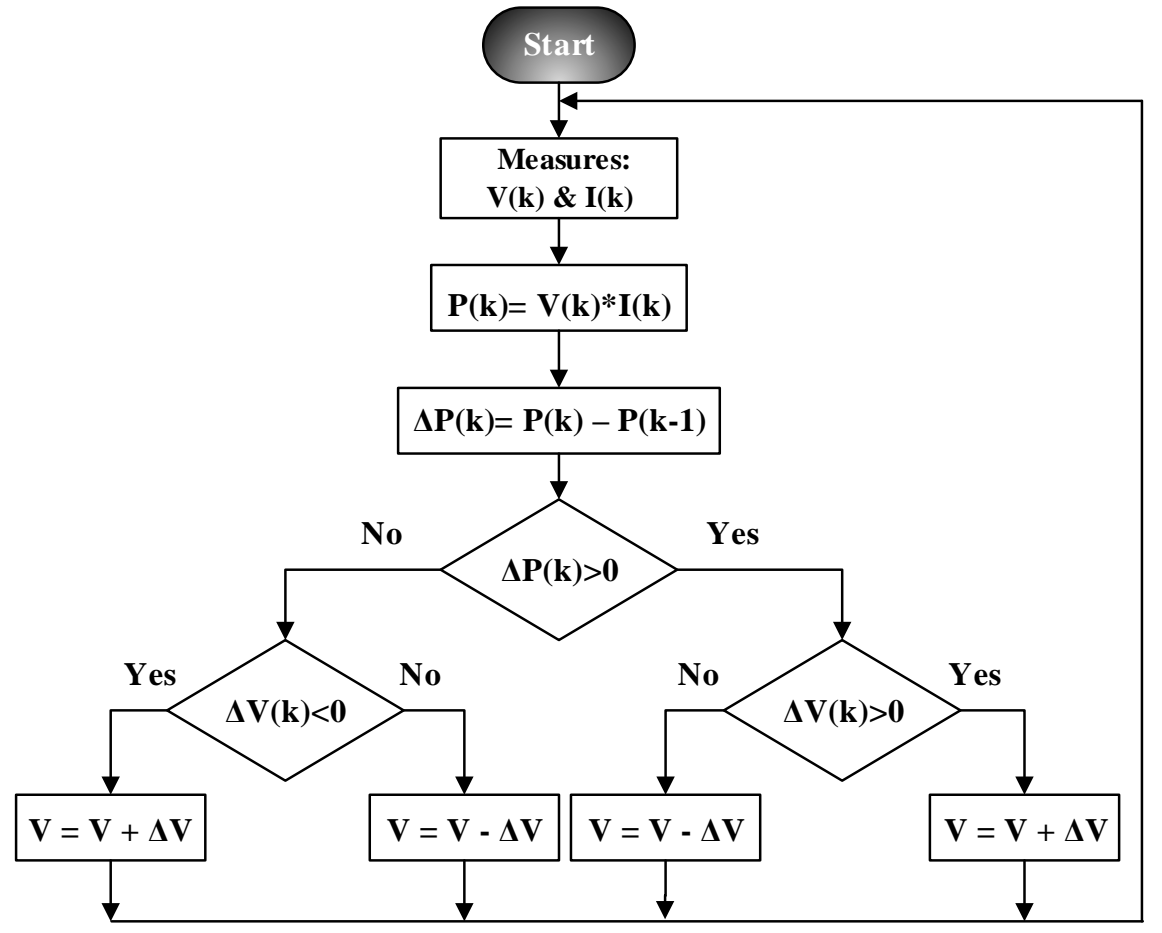

Figure 7. Perturb and observe method flowchart

The sliding mode control part is used to increase the control system accuracy based on the reference voltage predefined by the $\mathrm{P} \& \mathrm{O}$ algorithm. This technique is one of the most used non-linear controls due to its robustness and high precision, and its only disadvantage is the presence of the chattering phenomenon [16]. The SMC technique principle is based on two steps [12], the first is to define a surface called the sliding surface and the second is to define a control law called equivalent control. This last allows acting on the system to converge it to the sliding surface and to force it to stay in sliding mode on this surface in order to drive it to reach its optimum power point. The $\mathrm{U}_{\mathrm{smc}}$ control defined by the sliding mode control method is expressed by the following equation [15]:

$$
U_{s m c}=\left\{\begin{array}{lr}
0 & \text { for } U_{e q}+U_{n} \leq 0 \\
U_{e q}+U_{n} & \text { for } 0<U_{e q}+U_{n}<1 \\
1 & \text { for } U_{e q}+U_{n} \geq 0
\end{array}\right.
$$

where $U_{e q}$ is the equivalent control and $U_{n}$ represents the discrete control. However, to calculate this control, it is necessary to determine the sliding surface and the controls $U_{e q}$ and $U_{n}$.

- Sliding Surface [15]: Based on the system state at the maximum power point, where we find that $\mathrm{dp} / \mathrm{dv}=0$, we can choose the sliding surface as follows:

$$
S=\frac{d P_{p v}}{d V_{p v}}=I_{p v}+V_{p v} \cdot \frac{d I_{p v}}{d V_{p v}}=0
$$

Moreover, to improve this choice, using the reference voltage calculated by the P\&O algorithm, we could define a new surface expressed by the following relationship:

$$
S=\frac{d P}{d V}=\frac{P_{p v}-P_{r e f}}{V_{p v}-V_{r e f}}=I_{p v}+V_{r e f} \cdot \frac{d I_{p v}}{d V_{r e f}}
$$

with:

$$
P_{\text {ref }}=I_{p v} . V_{\text {ref }}
$$


where $\mathrm{V}_{\text {ref }}$ is the reference voltage calculate bye $\mathrm{P} \& \mathrm{O}$ technique and $\mathrm{I}_{\mathrm{pv}}$ is the PV panel output current.

- The equivalent control $\mathrm{U}_{\text {eq }}$ is defined from the following condition [15]:

$$
\dot{S}=\left[\frac{d s}{d X}\right]^{T} \dot{X}=0
$$

with:

$$
\dot{X}=\frac{d i_{p v}}{d t}=f(x)+g(x) \cdot U_{e q}
$$

According to the boost converter equation (9), we can conclude the expression of the equivalent control defined by:

$$
U_{e q}=-\frac{\left[\frac{d S}{d X}\right]^{T} \cdot f(x)}{\left[\frac{d S}{d X}\right]^{T} \cdot g(x)}=1-\frac{V_{p v}}{V_{o u t_{-} p v}}
$$

Moreover, in order to improve the system response time and optimize the maximum power point tracking, we proposed to use the same reference voltage defined by the $\mathrm{P} \& \mathrm{O}$ algorithm to calculate this control. The new equivalent control expression is as follows:

$$
U_{e q}=1-\frac{V_{\text {ref }}}{V_{\text {out_pv }}}
$$

- Finally, the discrete control $\mathrm{U}_{\mathrm{n}}$ is defined by [15]:

$$
U_{n}=K \cdot \operatorname{Sat}(S)
$$

with:

$$
\operatorname{Sat}(S)=\left\{\begin{array}{l}
\frac{S}{\varepsilon}, \quad \text { if }|S|<\varepsilon \\
\operatorname{Sign}(S), \text { Otherwise }
\end{array}\right.
$$

where $\mathrm{K}$ is a positive constant and $\varepsilon$ is the boundary layer thickness.

The objective of the fuzzy logic control part is to decrease the oscillations and reduce the chattering phenomenon effect around the MPP point and consequently increase the control system efficiency. The FLC controller is an intelligent technique widely used recently in the renewable energy systems control since it is better suited to non-linear systems; it can operate with imprecise inputs and does not require a system exact mathematical model. An FLC controller consists mainly of three parts: Fuzzification, Inference engine and Defuzzification [22, 23]. Figure 8 illustrates the sub-system implementation of proposed FLC controller [14].

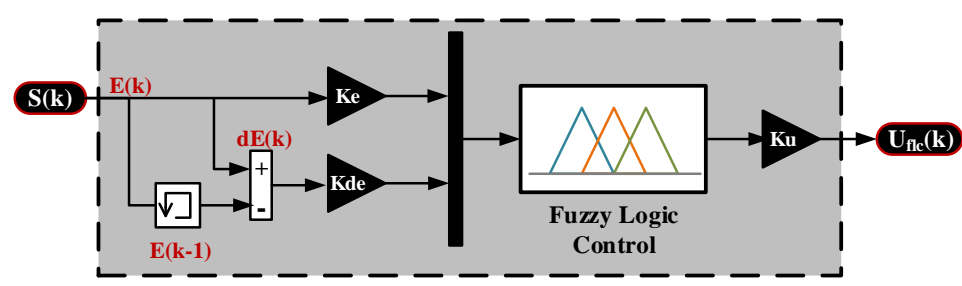

Figure 8. Block diagram of fuzzy logic MPPT controller

The fuzzy controller input variables are, the surface $\mathrm{S}$ (as error E) and its variation $\mathrm{dS}$ (as error variation $\mathrm{dE}$ ) which are defined by (23) and (24), and at the output, the controller generates the FLC equivalent control $\mathrm{U}_{\mathrm{flc}}$.

$$
E(k)=S(K)=\frac{P_{p v}(k)-P_{r e f}(k)}{V_{p v}(k)-V_{r e f}(k)}
$$




$$
d E(k)=d S(K)=E(k)-E(k-1)
$$

where $\mathrm{P}_{\mathrm{pv}}(\mathrm{k})$ and $\mathrm{V}_{\mathrm{pv}}(\mathrm{k})$ are the $\mathrm{PV}$ generator power and voltage, respectively.

The first step in the fuzzy controller operation is fuzzification, which consists of converting the input variables form from numeric to linguistic form based on membership functions. In our case, five fuzzy subsets are used and defined as: NB (negative big), NS (negative small), ZE (zero), PS (positive small) and PB (positive big). Figure 9 shows the memberships functions attributed to the input variables $S(k), d S(k)$ and the output variable $U_{\mathrm{flc}}(\mathrm{k})$. The second inference step allows, thanks to the MIN-MAX fuzzy implication method, to define membership rules to obtain logical relations between the controller input and output variables. Table 3 summarizes the 25 defined inference rules. In the last defuzzification step, the controller calculates the real numeric value of the output $\mathrm{U}_{\text {flc }}$ from its equivalent fuzzy subset, using the simplest and fastest center of gravity method [24].

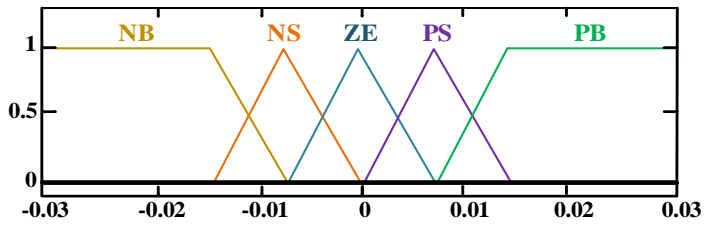

(a)

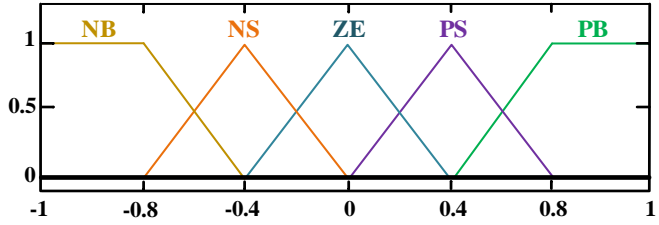

(b)

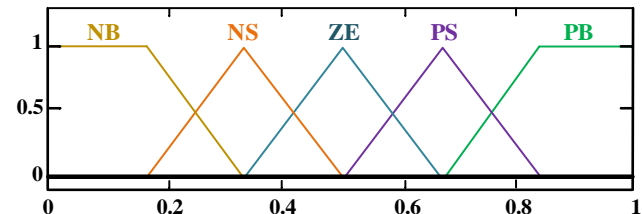

(c)

Figure 9. Membership functions for: (a) Input E, (b) Input $\mathrm{dE}$, (c) Output $\mathrm{U}_{\mathrm{flc}}$

Table 3. Fuzzy rules table for FLC controller

\begin{tabular}{cccccc}
\hline & & & $d E$ & & \\
NB & ZE & ZE & PE & PB & PB \\
NS & ZE & ZE & ZE & PS & PS \\
ZE & PB & PS & ZE & ZE & NS \\
PS & NS & NS & NB & ZE & ZE \\
PB & NS & NB & NB & ZE & ZE \\
\hline
\end{tabular}

\subsection{Proposed MPPT approach for wind system}

For the Wind system MPPT, we proposed a hybrid technique based on the two methods Hill Climbing Search (HCS) and Fuzzy Logic Control (FLC), with a step of calculating a reference power based on the knowledge of the wind turbine characteristics. Figure 10 illustrates the synoptic diagram of the proposed strategy. In order to calculate the control law $U_{\text {wind, }}$ it is first necessary to determine the reference variables $\mathrm{W}_{\text {ref }}$ and $\mathrm{P}_{\text {ref }}$, which are used later to define the fuzzy controller input variables.

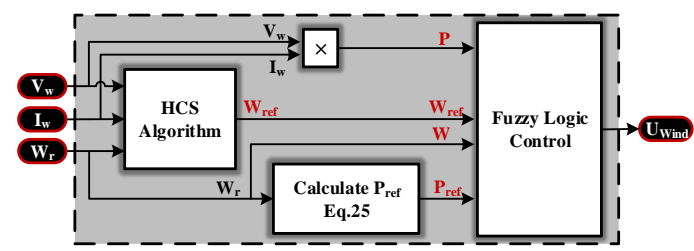

Figure 10. Block diagram of proposed MPPT approach for wind subsystem 
Using the HCS algorithm shown in Figure 11 [25], we can specify the reference rotor speed $\mathrm{W}_{\text {ref }}$ corresponding to an optimum power point, based on the perturbation of the wind turbine rotor speed with a small variation step $(\Delta \omega)$ and the observation of its effect on the PMSG generator output power. If a positive perturbation $(+\Delta \omega)$ increases the output power (case $\Delta \mathrm{P} / \Delta \omega>0$ ), the perturbation keeps the same direction until the power begins to decrease (case $\Delta \mathrm{P} / \Delta \omega<0$ ), at this moment, the perturbation must reverse the direction $(-\Delta \omega)$ to locate and follow the maximum power point (case $\Delta \mathrm{P} / \Delta \omega=0$ ). This algorithm is considered among the indirect methods most used in wind energy systems because of its independence to the wind turbine characteristics $\left(\mathrm{C}_{\mathrm{p}-\mathrm{opt}}\right.$ and $\left.\lambda_{\text {opt }}\right)$ and its implementation simplicity.

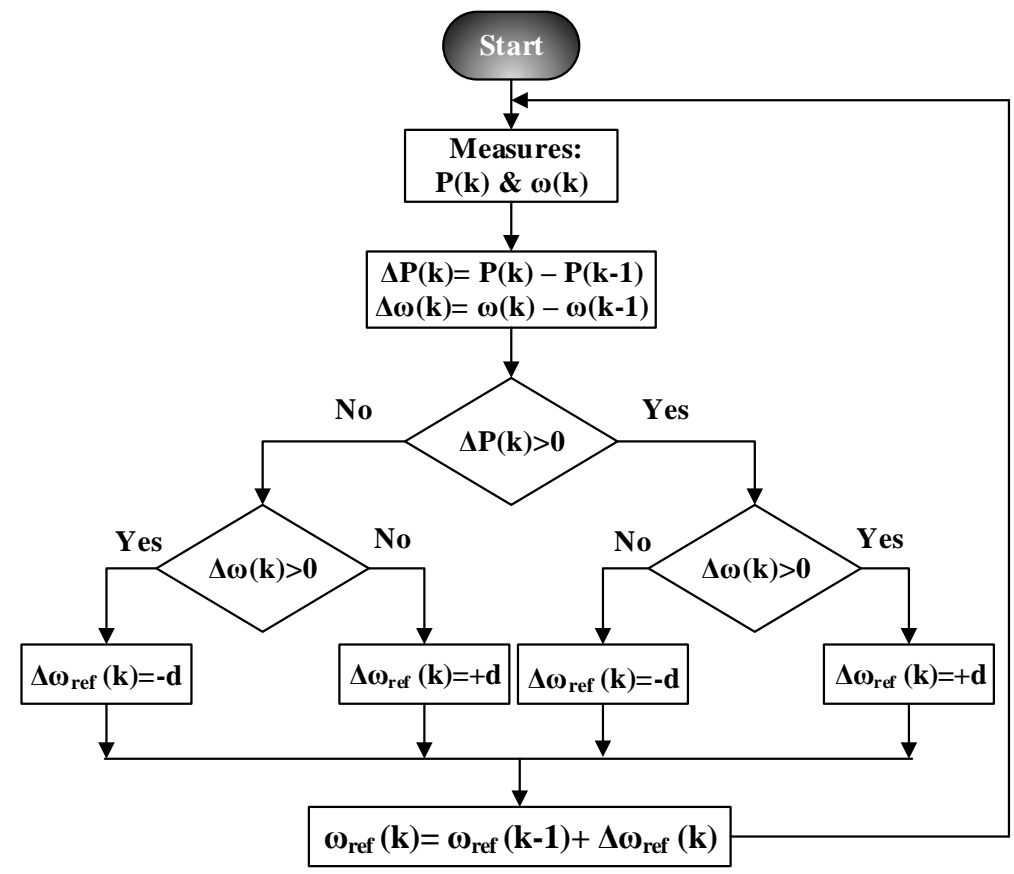

Figure 11. Hill climbing search method flowchart

To determine the reference power $\mathrm{P}_{\text {ref, }}$, the following equation is used [15]:

$$
P_{\text {ref }}=\frac{1}{2} \rho \pi R^{2} C_{\text {p.opt }} V_{\text {wind }}^{3}=K_{\text {opt }} . \omega_{\text {r.opt }}^{3}
$$

With:

$$
\begin{aligned}
& V_{\text {wind }}=\frac{\omega_{r . o p t} R}{\lambda_{o p t}} \\
& K_{o p t}=\frac{1}{2} \cdot \frac{\rho \cdot \pi \cdot R^{5} \cdot C_{p . o p t}}{\lambda_{o p t}^{3}}
\end{aligned}
$$

Where $\mathrm{K}_{\mathrm{opt}}$ is a constant calculated by the wind turbine characteristics.

Using these two reference parameters $\mathrm{W}_{\text {ref }}$ and $\mathrm{P}_{\text {ref, }}$, we define the fuzzy controller input variables as follows:

$$
\begin{aligned}
& E(k)=\frac{P(k)-P_{r e f}(k)}{\omega(k)-\omega_{r e f}(k)} \\
& d E(k)=E(k)-E(k-1)
\end{aligned}
$$

Where $\mathrm{E}(\mathrm{k})$ is the error, $\mathrm{dE}(\mathrm{k})$ is the change of error, $\mathrm{P}(\mathrm{k})$ and $\omega(\mathrm{k})$ are the output power and rotor speed of the wind system, respectively. Figure 12 illustrates the sub-system implementation of proposed FLC controller [14]. 


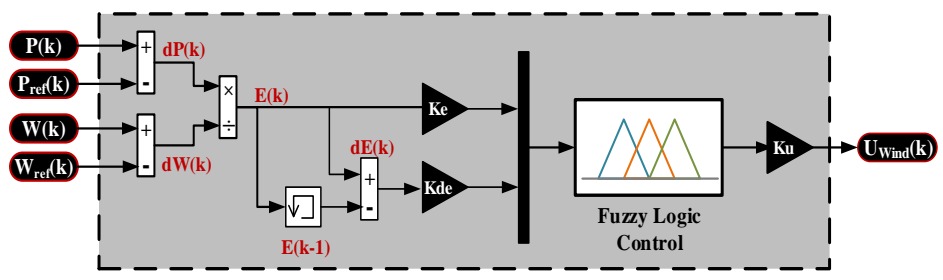

Figure 12. Block diagram of fuzzy logic MPPT controller

To calculate the output variable real value $\mathrm{U}_{\text {wind }}$, the fuzzy controller processes the input data following the same steps of fuzzification, inference engine and defuzzification explained in the PV system MPPT part. Figure 13 shows the memberships functions of the input variables $\mathrm{E}(\mathrm{k}), \mathrm{dE}(\mathrm{k})$ and the output variable $U_{\text {wind }}(k)$, using five fuzzy subsets: NB (negative big), NS (negative small), ZE (zero), PS (positive small) and PB (positive big). Table 4 shows the fuzzy rules designed by the MIN-MAX fuzzy implication method. Moreover, for the defuzzification step, we used the same center of gravity method [24].

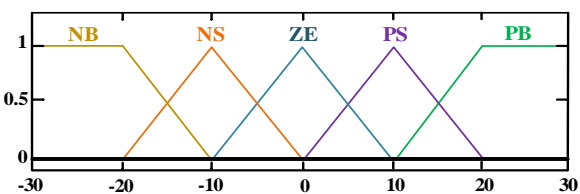

(a)

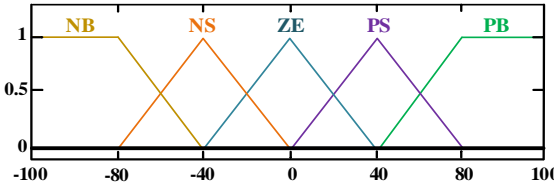

(b)

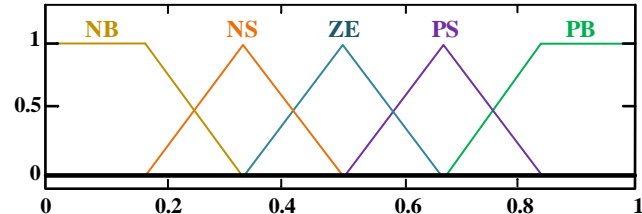

(c)

Figure 13. Membership functions for: (a) Input E, (b) Input dE, (c) Output $U_{\text {Wind }}$

Table 4. Fuzzy rules table for FLC controller

\begin{tabular}{cccccc}
\hline & NB & NS & ZE & PS & PB \\
\hline NB & NB & NB & NB & ZE & PS \\
NS & NB & NS & NS & ZE & PS \\
ZE & ZE & ZE & ZE & ZE & ZE \\
PS & NS & NS & NS & ZE & ZE \\
PB & NS & NB & NB & ZE & ZE \\
\hline
\end{tabular}

\section{SIMULATION RESULTS AND DISCUSSION}

In this work, a simulation of a hybrid power system is carried out under the Matlab/Simulink software, using the parameters of the various elements modeled previously. In order to optimize the performance of proposed PV/Wind/Batteries system, we have developed an MPPT controller based on robust algorithms to improve the power produced by the two PV and Wind sources. These approaches have been simulated, evaluated and compared with other methods, namely: Perturb and Observe (P\&O) [14], Fuzzy Logic Control (FLC) [14] and Robust Sliding Mode Control (RSMC) [15] for PV system, Hill Climbing Search (HCS) [14], Fuzzy Logic Control (FLC) [14] and Robust Sliding Mode Control (RSMC) [15] for Wind system. For a better verification and analysis study of the proposed commands, the simulations are made under variable operating conditions. Figure 14 shows the simulation results of the photovoltaic system corresponding to output power and voltage, under a solar irradiation change $\left(1000 \mathrm{~W} / \mathrm{m}^{2}\right.$ to $800 \mathrm{~W} / \mathrm{m}^{2}$, $800 \mathrm{~W} / \mathrm{m}^{2}$ to $600 \mathrm{~W} / \mathrm{m}^{2}$ and $600 \mathrm{~W} / \mathrm{m}^{2}$ at $1000 \mathrm{~W} / \mathrm{m}^{2}$, respectively) and at a constant temperature of $25^{\circ} \mathrm{C}$. Figure 15 shows the simulation results under a temperature change $\left(25^{\circ} \mathrm{C}\right.$ to $35^{\circ} \mathrm{C}, 35^{\circ} \mathrm{C}$ to $25^{\circ} \mathrm{C}$ and $25^{\circ} \mathrm{C}$ at $35^{\circ} \mathrm{C}$, respectively) and at a constant solar irradiation of $1000 \mathrm{~W} / \mathrm{m}^{2}$. 


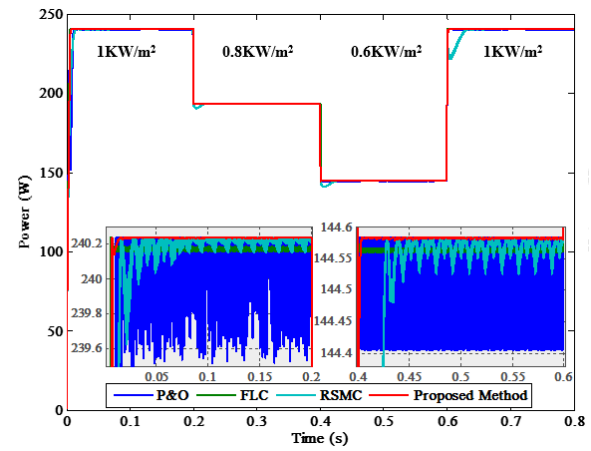

(a)

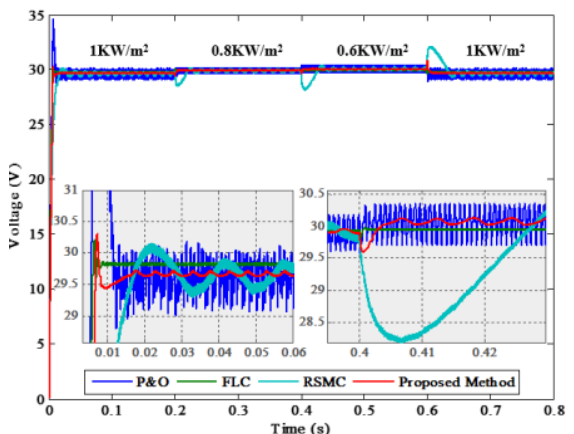

(b)

Figure 14. Simulation results of PV generator under varying irradiation levels, (a) Output power, (b) Output voltage

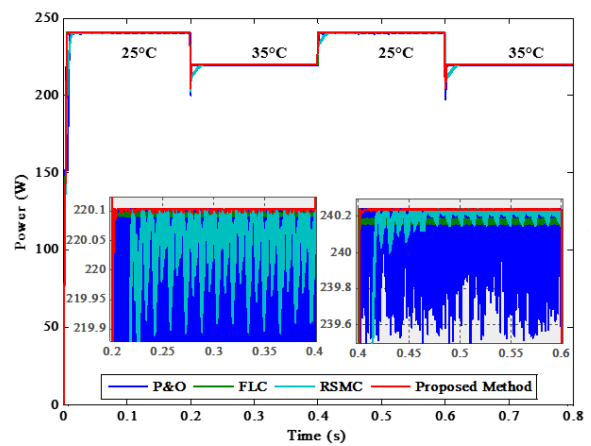

(a)

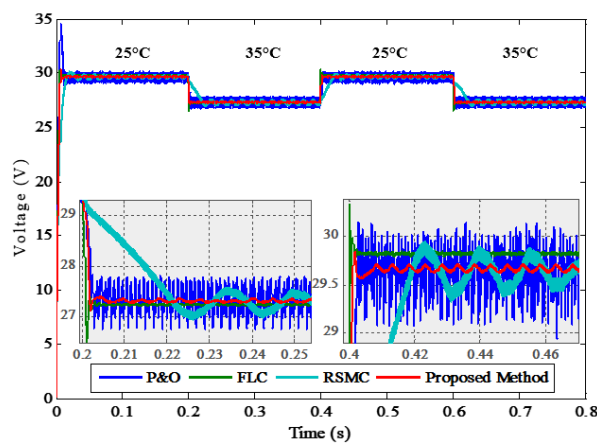

(b)

Figure 15. Simulation results of PV generator under varying temperature levels, (a) Output power, (b) Output voltage

From the analysis of these results and a critical comparison of the proposed approach with the other methods in accordance with: the system response time, the system behavior in transient and permanent regimes, the oscillations amplitude and frequency around MPP point and the obtained optimal output power. We can clearly notice that the $\mathrm{P} \& \mathrm{O}$ algorithm allows the system to reach an optimal power point less than the other methods with fast response time, but with significant oscillations that translates into a great loss of energy at the system output. The RSMC algorithm has good accuracy for finding the best optimal point in the steady state, but it is characterized by a poor transient behavior to stabilize the system at its optimal state and the presence of the chattering phenomenon with fewer oscillations around the MPP. The FLC technique has a faster response with very small oscillations, but the achieved power point remains less optimal than the other techniques. For the proposed control technique, the results show that whatever the climatic conditions (irradiation and temperature), the system reaches and tracks its MPP point that is the largest with a very good transient and steady state behavior, which translates into a better response time about $0.01 \mathrm{~s}$, a negligible oscillations, and a very good stability and accuracy.

From an efficiency viewpoint, the proposed approach has a significant value of about 99,57\% compared to P\&O, RSMC and FLC methods that have efficiencies of 98.72\%, 99.24\%, and 99,45\% respectively. For that, we can conclude that this hybrid technique is more efficient, very robust and has very good performances, which allows improving and optimizing the PV subsystem energy productivity. Figure 16 shows the simulation results of the wind system corresponding to output mechanical power and power coefficient, under a wind speed change $(12 \mathrm{~m} / \mathrm{s}$ to $10 \mathrm{~m} / \mathrm{s}$ and $10 \mathrm{~m} / \mathrm{s}$ to $12 \mathrm{~m} / \mathrm{s}$ respectively). According to the verification of obtained results for the various techniques applied to our wind energy subsystem, we observe that the HCS algorithm imposes a great loss of energy because it allows achieving a very low stability point with slow response and significant oscillations. The FLC technique has a fast response, fewer oscillations compared to RSMC and HCS and good stability around its optimal point in the steady state. The RSMC method has high sensitivity to changes in wind speed translates to poor transient behavior, it is also characterized by a slower response than the FLC technique with the same problem of 
chattering phenomenon in steady state. For the developed approach it is found that whatever the wind speed levels, this command allows thanks to a great stability and precision, a good time dynamic response of $0.45 \mathrm{~s}$ and fewer oscillations to reach and track a more optimal power point MPP than the other methods.

From an efficiency viewpoint, the proposed technique has a significant value of about $99,75 \%$ compared to HCS, RSMC and FLC methods that have efficiencies of 91.4\%, 99.47\%, and 99,64\% respectively. Consequently, it can be said that this approach increases the Wind subsystem efficiency with remarkable advantages and better performances.

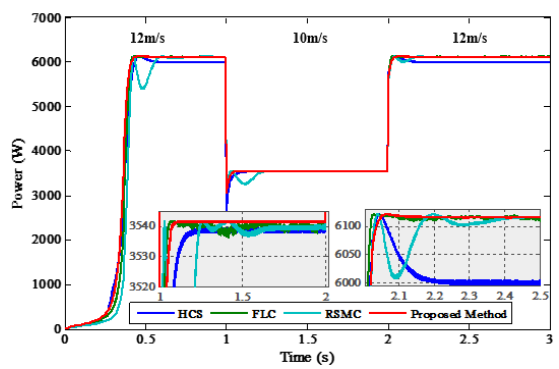

(a)

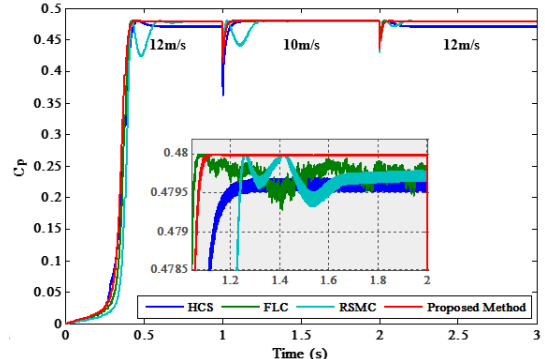

(b)

Figure 16. Simulation results of wind generator under varying wind speed levels, (a) Output power, (b) Power coefficient

\section{CONCLUSION AND PERSPECTIVES}

In this work, a modeling and optimization study of a PV/Wind/Batteries hybrid energy system was carried out, with the aim of improving its energy performance and optimize its use in isolated sites. An MPPT controller has been developed based on two hybrid approaches, in order to increase the PV and Wind subsystems efficiency by better tracking of their optimal power point using the control of the two system boost converters. The simulations results show that the designed MPPT techniques allow, whatever the climatic changes, to improve the productivity of both energy productions chains with good performances and significantly higher efficiency compared to other methods developed in the literature. As a perspective of our work, we thought on the one hand to develop other intelligent MPPT approaches for both PV and Wind systems, and on the other hand, the development of an energy management strategy of a standalone hybrid energy system.

\section{REFERENCES}

[1] O. Zebraoui and M. Bouzi, "Sizing and optimization of a fully autonomous hybrid PV-Wind power system," IEEE International Conference on Electrical Sciences and Technologies in Maghreb (CESTIM), pp. 227-233, 2016.

[2] S.S. Martin, A. Chebak, A. El Ouafi and M. Mabrouki, "Modeling and simulation of hybrid power system integrating wind, solar, biodiesel energies and storage battery," IEEE International Renewable and Sustainable Energy Conference (IRSEC16), pp. 457-463, 2016.

[3] M. E. Azzaoui, H. Mahmoudi and K. Boudaraia, "Backstepping control of wind and photovoltaic hybrid renewable energy system," International Journal of Power Electronics and Drive Systems (IJPEDS), vol. 7(3), pp. 677-686, 2016.

[4] S. Das and A. K. Akella, "Power flow control of PV-wind-battery hybrid renewable energy systems for stand-alone application," International Journal of Renewable Energy Research (IJRER), vol. 8(1), pp. 36-43, 2018.

[5] D. Shen, A. Izadian and P. Liao, "A hybrid wind-solar-storage energy generation system configuration and control," IEEE Energy Conversion Congress and Exposition (ECCE), Pittsburgh, PA, USA, pp. 436-442, 2014.

[6] A. Jemaa, O. Zarrad, M. A. Hajjaji and M. N. Mansouri, "Hardware implementation of a fuzzy logic controller for a hybrid wind-solar system in an isolated site," International Journal of Photoenergy, vol. 2018, pp. 1-16, 2018.

[7] S. Ahmed, C. Benoudjafer and C. Benachaiba, "MPPT technique for standalone hybrid PV-Wind using fuzzy controller," In: Hatti M. (eds) Artificial Intelligence in Renewable Energetic Systems (ICAIRES 2017), Lecture Notes in Networks and Systems, vol. 35, pp. 185-196, 2018.

[8] H. Abouobaida and S. El Beid, "Practical performance evaluation of maximum power point tracking algorithms in a photovoltaic system," International Journal of Power Electronics and Drive System (IJPEDS), vol. 8(4), pp. 1744-1755, 2017.

[9] D. Kumar and K. Chatterjee, "A review of conventional and advanced MPPT algorithms for wind energy systems," Renewable and Sustainable Energy Reviews, vol. 55, pp. 957-970, 2016. 
[10] H. Belmili, S. Boulouma, B. Boualem and A.M. Fayçal, "Optimized control and sizing of standalone PV-Wind energy conversion system," Energy Procedia, vol. 107, pp. 76-84, 2016.

[11] M. Slimi, A. Boucheta and B. Bouchiba, "Maximum power control for photovoltaic system using intelligent strategies," International Journal of Power Electronics and Drive System (IJPEDS), vol. 10(1), pp. 423-432, 2019.

[12] C. H. Tran, F. Nollet, N. Essounbouli and A. Hamzaoui, "Modeling and simulation of standalone photovoltaic system using three level boost converter," IEEE International Renewable and Sustainable Energy Conference (IRSEC17), Tangier, Morocco, pp. 1-6, 2017.

[13] Y. Soufi, S. Kahla and M. Bechouat, "Particle swarm optimization based sliding mode control of variable speed wind energy conversion system," International Journal of Hydrogen Energy, vol. 41(45), pp. 20956-20963, 2016.

[14] O. Zebraoui and M. Bouzi, "Fuzzy logic based MPPT control for a PV/Wind hybrid energy system," IEEE International Renewable and Sustainable Energy Conference (IRSEC17), Tangier, Morocco, pp. 1-6, 2017.

[15] O. Zebraoui and M. Bouzi, "Robust Sliding Mode Control based MPPT for a PV/Wind Hybrid Energy System," International Journal of Intelligent Engineering and Systems (IJIES), vol. 11(5), pp. 290-300, 2018.

[16] S. Miqoi, A. El Ougli and B. Tidhaf, "Adaptive fuzzy sliding mode based MPPT controller for a photovoltaic water pumping system," International Journal of Power Electronics and Drive System (IJPEDS), vol. 10(1), pp. 414-422, 2019.

[17] A. Pradipta, D. C. Ridwan and Soedibyo, "Power flow control of battery energy storage system using droop voltage regulation technique integrated with hybrid PV/Wind generation system," International Conference on Information and Communications Technology (ICOIACT), Yogyakarta, Indonesia, pp. 202-207, 2018.

[18] S. Marmouh, M. Boutoubat and L. Mokrani, "Performance and power quality improvement based on DC-bus voltage regulation of a stand-alone hybrid energy system," Electric Power Systems Research, vol. 163, pp. 73-84, 2018.

[19] S. Assahout, H. Elaissaoui, A. El Ougli, B. Tidhaf and H. Zrouri, "A neural network and fuzzy logic based MPPT algorithm for photovoltaic pumping system," International Journal of Power Electronics and Drive System (IJPEDS), vol. 9(4), pp. 1823-1833, 2018.

[20] H. Abouobaida and S. El Beid, "New MPPT control for wind conversion system based PMSG and a comparaison to conventionals approachs," 14th International Multi-Conference on Systems Signals \& Devices (SSD), Marrakech, Morocco, pp. 38-43, 2017.

[21] M. Elyaqouti, S. Hakim, S. Farhat, L. Bouhouch and A. Ihlal, "Implementation in arduino of MPPT using variable step size $\mathrm{P} \& \mathrm{O}$ algorithm in PV installations," International Journal of Power Electronics and Drive System (IJPEDS), vol. 8(1), pp. 434-443, 2017.

[22] T. Laagoubi, M. Bouzi and Mohamed Benchagra, "MPPT \& power factor control for grid connected PV systems with fuzzy logic controllers," International Journal of Power Electronics and Drive System (IJPEDS), vol. 9(1), pp. 105-113, 2018.

[23] A. S. Samosir, H Gusmedi, S. Purwiyanti and E. Komalasari, "Modeling and simulation of fuzzy logic based maximum power point tracking (MPPT) for PV application," International Journal of Electrical and Computer Engineering (IJECE), vol. 8, no. 3, pp. 1315-1323, 2018.

[24] D. M. Atia and H. T. El-madany, "VHDL based maximum power point tracking of photovoltaic using fuzzy logic control," International Journal of Electrical and Computer Engineering (IJECE), vol. 7(6), pp. 3454-3466, 2017.

[25] O. Zebraoui and M. Bouzi, "Comparative study of different MPPT methods for wind energy conversion system," IOP Conf. Series: Earth and Environmental Science, vol. 161, pp. 1-9, 2018. 